Correction

\title{
Correction: Akosah-Twumasi, Peter, et al. 2020. Prioritising Family Needs: A Grounded Theory of Acculturation for Sub-Saharan African Migrant Families in Australia. Social Sciences 9: 17
}

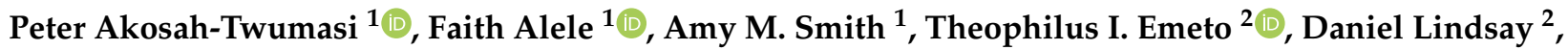 \\ Komla Tsey ${ }^{3}$ and Bunmi S. Malau-Aduli ${ }^{1, *(D)}$
}

1 College of Medicine and Dentistry, James Cook University, Townsville, QLD 4811, Australia; peter.akosahtwumasi@my.jcu.edu.au (P.A.-T.); faith.alele@my.jcu.edu.au (F.A.); amy.smith@my.jcu.edu.au (A.M.S.)

2 College of Public Health, Medical and Veterinary Sciences, James Cook University, Townsville, QLD 4811, Australia; theophilus.emeto@jcu.edu.au (T.I.E.); daniel.lindsay1@jcu.edu.au (D.L.)

3 College of Arts, Society and Education, James Cook University, Cairns, QLD 4870, Australia; komla.tsey@jcu.edu.au

* Correspondence: bunmi.malauaduli@jcu.edu.au

\section{check for} updates

Citation: Akosah-Twumasi, Peter, Faith Alele, Amy M. Smith,

Theophilus I. Emeto, Daniel Lindsay, Komla Tsey, and Bunmi S.

Malau-Aduli. 2021. Correction:

Akosah-Twumasi, Peter, et al. 2020.

Prioritising Family Needs: A

Grounded Theory of Acculturation

for Sub-Saharan African Migrant

Families in Australia. Social Sciences 9:

17. Social Sciences 10: 73. https://

doi.org/10.3390/socsci10020073

Received: 8 February 2021

Accepted: 9 February 2021

Published: 19 February 2021

Publisher's Note: MDPI stays neutral with regard to jurisdictional claims in published maps and institutional affiliations.

Copyright: (c) 2021 by the authors. Licensee MDPI, Basel, Switzerland. This article is an open access article distributed under the terms and conditions of the Creative Commons Attribution (CC BY) license (https:/ / creativecommons.org/licenses/by/ $4.0 /)$.
The authors wish to make the following change to their paper (Akosah-Twumasi et al 2020). The materials and methods under section "Data Analysis" incorrectly references a paper (Charmaz 2014). The correct version of Section 2.4. "Data Analysis" is as follows:

\subsection{Data Analysis}

The analysis process followed Corbin and Strauss's three phases of coding: open, axial, and selective (Corbin and Strauss 1990). In open coding, the transcribed interviews were examined line-by-line to develop the initial coding for descriptive categories. Axial coding was carried out to establish the relationships between the developed categories (Corbin and Strauss 1990).

Conflicts of Interest: The authors declare no conflict of interest.

\section{References}

Akosah-Twumasi, Peter, Faith Alele, Amy M. Smith, Theophilus I. Emeto, Daniel Lindsay, Komla Tsey, and Bunmi S. Malau-Aduli. 2020. Prioritising Family Needs: A Grounded Theory of Acculturation for Sub-Saharan African Migrant Families in Australia. Social Sciences 9: 17. [CrossRef]

Corbin, Juliet, and Anselm Strauss. 1990. Grounded theory research: Procedures, canons, and evaluative criteria. Qualitative Sociology 13: 3-21. [CrossRef] 